\title{
An arachnoid cyst presenting as an intramedullary tumour
}

P W A Willems, W M van den Bergh, W P Vandertop

\begin{abstract}
A case of thoracic intradural extramedullary arachnoid cyst is presented in which an intramedullary low grade glioma was suspected preoperatively. The cyst was widely fenestrated and postoperatively, the patient experienced considerable improvement in her symptoms. As postoperative MRI studies also showed resolution of the intramedullary changes we regard the intramedullary changes as a result of the cyst, without the existence of primary medullary pathology. To our knowledge an arachnoid cyst, to date, has not been described as the cause of syringomyelia. As radiological findings can be misleading, extramedullary pathology, located more cranially, should be ruled out when treating cystic medullary changes.

(F Neurol Neurosurg Psychiatry 2000;68:508-510)
\end{abstract}

Keywords: intradural arachnoid cyst; thoracic spine; syringomyelia; spinal cord compression

Department of

Neurosurgery,

University Hospital

Utrecht, G03.124, PO

Box 85500, NL-3508

GA, Utrecht, The

Netherlands

P W A Willems

W $M$ van den Bergh

Department of

Neurosurgery,

University Hospital

Vrije Universiteit, PO

Box 7057, NL-1007

MB, Amsterdam, The

Netherlands

W P Vandertop

Correspondence to: Dr P W A Willems,

Department of

Neurosurgery, University

Hospital Utrecht, G03.124,

PO Box 85500, NL-3508

GA, Utrecht, The

Netherlands

email p.willems@

neuro.azu.nl

Received 30 April 1999 and in revised form

14 October 1999

Accepted 26 October 1999

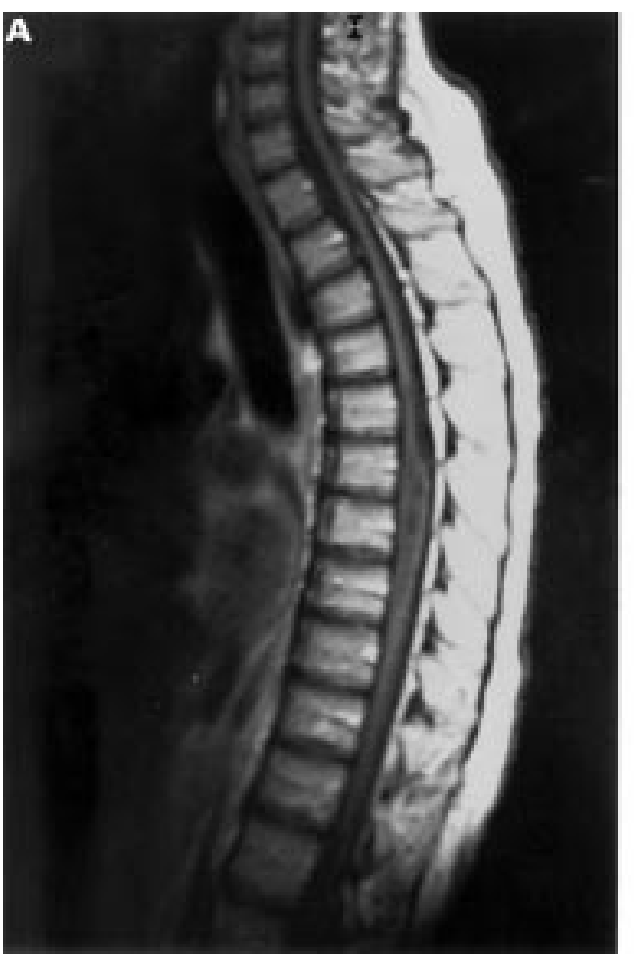

Arachnoid cysts are a rare cause of spinal cord compression, ${ }^{12}$ although they are often encountered as incidental asymptomatic findings in examinations performed for other reasons. ${ }^{2}$ Although their radiological features have been well described, ${ }^{2-4}$ they may be underrecognised due to incomplete diagnostic programmes. ${ }^{25}$ We report on a patient with a symptomatic intradural arachnoid cyst, located on the dorsal aspect of the thoracic spinal cord, presenting with unusual and misleading radiological findings, delaying correct diagnosis until the operation.

\section{Case report}

A 50 year old woman was admitted to our hospital with a progressive walking disorder. Since 1985 she experienced loss of control over her legs, predominantly on the right side. The upper limbs were not involved. Micturition and defecation were undisturbed. There was no relevant medical history besides an ankle fracture in 1977.

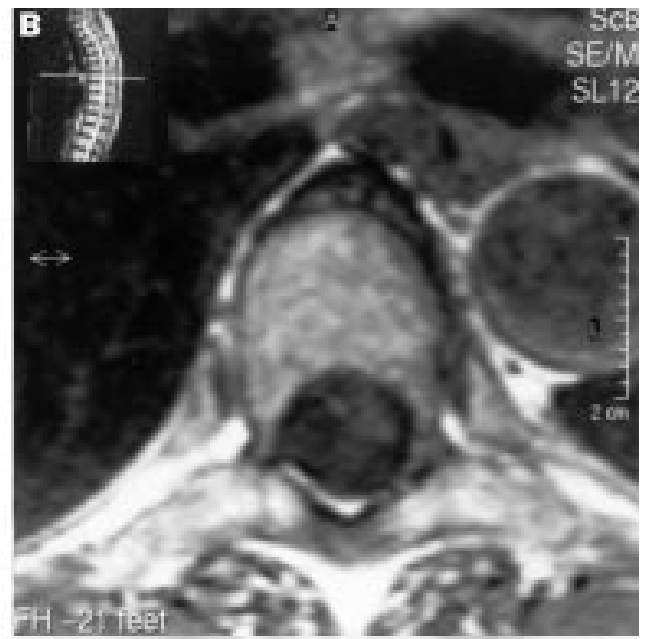

Figure 1 (A) Preoperative sagittal MRI of the thoracic spinal cord after Gd-DTPA administration, showing enlargement of the cord, without pathological enhancement. (B) Preoperative transverse MRI of the thoracic spinal cord, just above the enlargement of the spinal cord. Left anterior displacement and compression of the cord is suggested. Retrospectively, this is most likely due to the arachnoid cyst. 


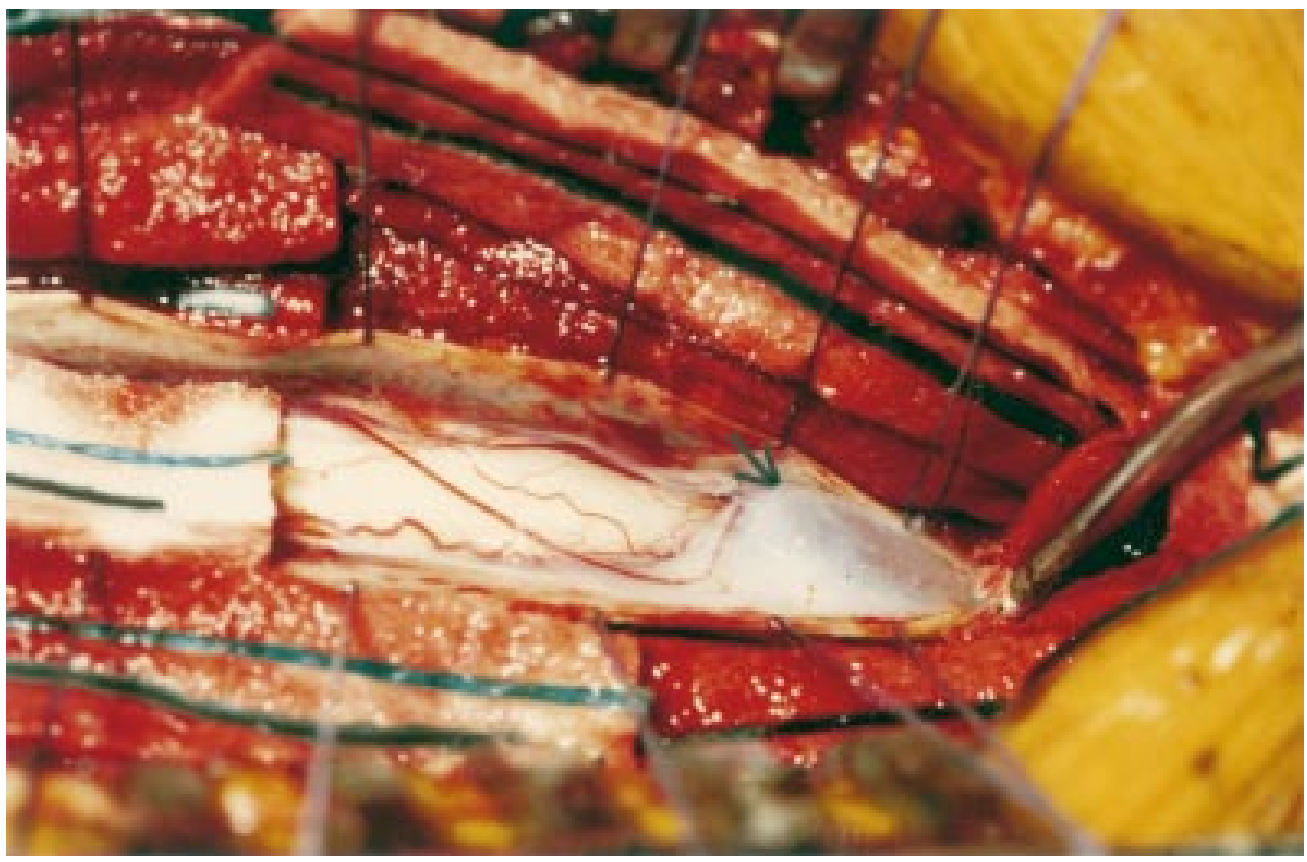

Figure 2 Intraoperative photograph (after laminectomy and opening and tenting of the dura) clearly showing the arachnoid cyst (arrow) cranial to a pathologically swollen spinal cord with distorted blood vessels.

When first seen by a neurologist in May 1985 , a spastic paraparesis was diagnosed, predominantly on the right side, with intact sensibility. No abnormalities were present in brainstem evoked potential, visual evoked potential and electric nystagmography. Investigation of the CSF showed two bands with normal IgG index. When repeated in 1987, the CSF was normal. A tentative diagnosis of "spastic spinal paralysis" was made. A conservative policy was followed, without further neuroradiological follow up.

After years of slow progression of her symptoms there was a sudden deterioration in her condition in 1996. Then, for the first time, MRI of the spine was made. Under suspicion

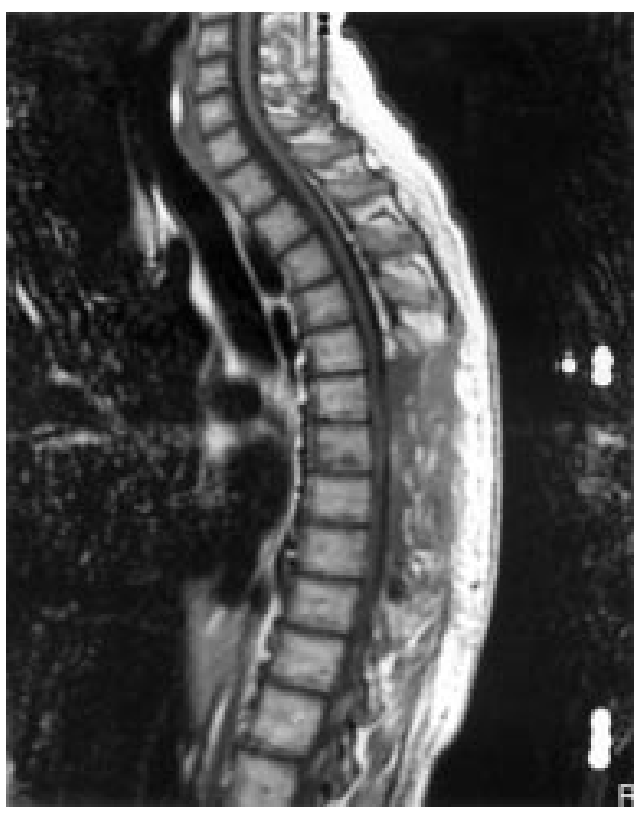

Figure 3 Postoperative sagittal MRI of the thoracic spinal cord. The intramedullary changes have almost disappeared. of an intramedullary tumour the patient was referred to our hospital.

EXAMINATION

On neurological examination muscle strength of the right leg was proximally MRC grade 4+ and distally MRC grade 4 . Sense of pain was diminished bilaterally from level Th7-8. Other sensory modalities were undisturbed. The coordination of her right leg was severely disturbed. Deep tendon reflexes of both legs were increased, on the right side more pronounced than on the left, with subclonic Achilles tendon reflexes and bilateral pathological plantar responses.

Repeat MRI of the thoracic spine showed a cystic enlargement of the thoracic spinal cord from T6 to T9, with no enhancement after intravenous administration of contrast medium (fig 1). An intramedullary cystic astrocytoma was suspected.

\section{OPERATION}

After laminectomy from T5-7, transdural ultrasound clearly showed the sudden change in spinal cord diameter at level T6. The dura was opened in the midline and, surprisingly, a more or less transparent extramedullary cystic lesion was encountered, just cranial to the swollen spinal cord (fig 2), obviously compressing the cord on the right. Suspicion arose that the medullary changes were the result of this cystic lesion, without the existence of primary medullary pathology. The cyst was partially resected and widely fenestrated. Histological examination of the resected cyst wall confirmed the diagnosis of an arachnoid cyst.

\section{POSTOPERATIVE COURSE}

Postoperatively a remarkable improvement in neurological performance was noted, and an 
MRI study of the thoracic spine 9 days postoperatively showed a clear improvement in the spinal cord. On the 10th day postoperatively, the patient was discharged. An MRI 3 months later showed further resolution of the medullary abnormalities (fig 3).

\section{Discussion}

Spinal arachnoid cysts are a rare cause of spinal cord compression and generally assumed to be congenital in origin. ${ }^{1256}$ It has been postulated that proliferation of arachnoid trabeculae is responsible for their occurrence. They are most commonly situated dorsal to the thoracic spinal cord, more often extradurally than intradurally. Their clinical course may extend over several years with fluctuation of symptoms, as in our patient, possibly due to emptying and refilling of the cyst. ${ }^{126}$ The neurological symptoms and signs in our patient at the moment of referral were attributed to the intramedullary changes seen on the MRI. However, the presence of a more cranially located space occupying arachnoid cyst could also explain the clinical picture. Therefore, on clinical grounds, the arachnoid cyst was indistinguishable from an intramedullary lesion.

Previously, arachnoid cysts have been reported to exist in association with a syringeal cavity; however, not until after spinal trauma or surgery. ${ }^{7}$ Although the aetiology of both conditions - that is, cyst and syrinx - is still incompletely understood, trauma was suspected to be the common cause of both findings in these patients. A causal relation between the two has, to date, not been described.

Whereas conventional myelography or CT myelography can demonstrate contrast filling of a communicating arachnoid cyst, or a contrast defect in the case of a noncommunicating cyst, ${ }^{235} \mathrm{MRI}$ can distinguish an extradural cyst from surrounding fat. In the case of an intradural cyst it is sometimes difficult to identify its borders, ${ }^{3}$ as was the case in our patient, although medullary compression and dislocation may show its location and extension. Cine mode MRI has recently been shown to be more sensitive than MRI in detecting the septation of the subarachnoid space. ${ }^{3}$ Thus typical radiological findings can assist in ruling out arachnoid cysts.

Earlier suggestions for syrinx formation include post-traumatic conditions, ${ }^{4}$ hydrodynamic changes associated with arachnoiditis, ${ }^{8}$ or developmental abnormalities and spinal cord compression resulting in spinal cord ischaemia (myelomalacia). ${ }^{9}$ Although intramedullary tumours are often associated with a syringeal cavity $(25 \%-60 \%)$, extramedullary tumours rarely cause syrinx formation. ${ }^{10}$ In our patient the syrinx was located caudally to the level of the arachnoid cyst, suggesting cyst induced hydrodynamic changes involving interstitial CSF backflow, ${ }^{8}$ rather than a direct effect of spinal cord compression. Arachnoid cysts have been reported in association with a more cranial syrinx, ${ }^{11}{ }^{12}$ suggesting either another pathophysiological mechanism or a mere coincidental finding.

\section{Conclusion}

Resolution of a syrinx established by MRI after arachnoid cyst marsupialisation, where the syrinx is located caudally to the cyst, has not been reported before. The improvement in the neurological condition of our patient postoperatively, strongly suggests a causal relation between the two findings. Consequently, extramedullary pathology, including arachnoid cysts, should be ruled out when intramedullary pathology suggesting syrinx formation is found. ${ }^{13}$

1 Galzio RJ, Zenobii M, Lucantoni D, et al. Spinal intradural arachnoid cyst. Surg Neurol 1982;17:388-91.

2 Gimeno A. Arachnoid, neurenteric and other cysts. In: Vinken PJ, Bruyn GW, eds. Handbook of clinical neurology. Vol 32. Congenital malformations of the spine and spinal cord. Amsterdam: North-Holland, 1978:393-448.

3 Fujimura M, Tominaga T, Koshu K, et al. Cine-mode magnetic resonance imaging of a thoracic intradural arachnoid cyst: case report. Surg Neurol 1996;45:533-6.

4 Williams B, Terry AF, Jones HWF. Syringomyelia as a sequel to traumatic paraplegia. Paraplegia 1981;19:67-80.

sequel to traumatic paraplegia. Paraplegia 1981;19:67-80.
Nabors MW, Pait TG, Byrd EB, et al. Updated assessment and current classification of spinal meningeal cysts. $\mathcal{F} \mathrm{Neu}$ and current classification

6 Chen $\mathrm{H}$, Chen L. Traumatic interdural arachnoid cyst in the upper cervical spine. $\mathcal{F}$ Neurosurg 1996;85:351-3.

7 Andrews BT, Weinstein PR, Rosenblum ML, et al. Intradural arachnoid cysts of the spinal cord associated with intramedullary cysts. $\mathcal{F}$ Neurosurg $1988 ; 68: 544-9$

8 Klekamp J, Batzdorf U, Samii M, et al. Treatment of syringomyelia associated with arachnoid scarring caused by arachnoiditis or trauma. F Neurosurg 1997;86:233-40.

9 Foster JB, Hudgson P. The pathology of communicating syringomyelia. In: Barnett HJM, Foster JB, Hodgson P, eds. Syringomyelia. Major problems in neurology. London: Saunders,W.B. 1973:79-103.

10 Barnett HJM, Rewcastle NB. Syringomyelia and tumours of the nervous system. In: Barnett HJM, Foster JB, Hodgson $\mathrm{P}$, eds. Syringomyelia. Major problems in neurology. London: PB Saunders, 1973:261-301.

11 Tabor EN, Batzdorf U. Thoracic spinal pantopaque cyst and associated syrinx resulting in progressive spastic paraparesis: case report. Neurosurgery 1996;39:1040-2.

12 Clifton AG, Ginsberg L, Webb WJS, et al. Idiopathic spinal arachnoid cyst and syringomyelia. Br f Radiology 1987;60: $1023-5$

13 Mallucci CL, Stacey RJ, Miles JB, et al. Idiopathic syringomyelia and the importance of occult arachnoid webs, pouches and cysts. Br F Neurosurg 1997;11:306-9. 